\title{
Review
}

\section{Clinical and Imaging Predictors of Recurrent Ischemic Stroke: A Systematic Review and Meta-Analysis}

\author{
Frans Kauw $^{a}$ Richard A.P. Takx ${ }^{a}$ Hugo W.A.M. de Jong ${ }^{a}$ Birgitta K. Velthuis ${ }^{a}$ \\ L. Jaap Kappelle ${ }^{b}$ Jan.W. Dankbaar ${ }^{a}$ \\ ${ }^{a}$ Department of Radiology, University Medical Center Utrecht, University of Utrecht, Utrecht, The Netherlands; \\ ${ }^{b}$ Department of Neurology and Neurosurgery, Brain Center Rudolf Magnus, University Medical Center Utrecht, \\ University of Utrecht, Utrecht, The Netherlands
}

\section{Keywords}

Ischemic stroke - Recurrent stroke · Predictors of outcome · Imaging in stroke $\cdot$ Meta-analysis

\begin{abstract}
Background: Predictors of recurrent ischemic stroke are less well known in patients with a recent ischemic stroke than in patients with transient ischemic attack (TIA). We identified clinical and radiological factors for predicting recurrent ischemic stroke in patients with recent ischemic stroke. Methods: A systematic search in PubMed, Embase, Cochrane Library, and CINAHL was performed with the terms "ischemic stroke," "predictors/determinants," and "recurrence." Quality assessment of the articles was performed and the level of evidence was graded for the articles included for the metaanalysis. Pooled risk ratios (RR) and heterogeneity $\left(I^{2}\right)$ were calculated using inverse variance random effects models. Results: Ten articles with high-quality results were identified for meta-analysis. Past medical history of stroke or TIA was a pre-
\end{abstract}

dictor of recurrent ischemic stroke (pooled RR $2.5,95 \% \mathrm{Cl}$ 2.1-3.1). Small vessel strokes were associated with a lower risk of recurrence than large vessel strokes (pooled RR 0.3, $95 \% \mathrm{Cl} 0.1-0.7)$. Patients with stroke of an undetermined cause had a lower risk of recurrence than patients with large artery atherosclerosis (pooled RR $0.5,95 \% \mathrm{Cl} 0.2-1.1$ ). We found no studies using CT or ultrasound for the prediction of recurrent ischemic stroke. The following MRI findings were predictors of recurrent ischemic stroke: multiple lesions (pooled RR 1.7, 95\% Cl 1.5-2.0), multiple stage lesions (pooled RR 4.1, 95\% Cl 3.1-5.5), multiple territory lesions (pooled RR 2.9, 95\% Cl 2.0-4.2), chronic infarcts (pooled RR 1.5, 95\% Cl 1.2-1.9), and isolated cortical lesions (pooled RR 2.2, 95\% Cl 1.5-3.2). Conclusions: In patients with a recent ischemic stroke, a history of stroke or TIA and the subtype large artery atherosclerosis are associated with an increased risk of recurrent ischemic stroke. Predictors evaluated with MRI include multiple ischemic changes and isolated cortical lesions. Predictors of recurrent ischemic stroke concerning $\mathrm{CT}$ or ultrasound have not been published.

(c) 2018 The Author(s)

Published by S. Karger AG, Basel 


\section{Introduction}

Patients with a recent ischemic stroke are at risk for a second ischemic stroke with reported 1-year-incidence rates ranging from $8 \%$ to $14 \%$ [1-3]. In contrast to patients with transient ischemic attack (TIA), predictors of recurrent ischemic stroke in patients with a recent ischemic stroke are less well known. Clinical factors such as stroke subtype and past medical history of stroke have been reported to be associated with recurrent ischemic stroke $[4,5]$. Over the last decade, radiological findings have gained more interest in predicting recurrent stroke. For instance, several studies that were based on findings of transesophageal echocardiography or cardiac CT angiography have reported associations between certain aortic plaque characteristics and recurrent hemorrhagic or ischemic stroke [6-8]. However, most imaging studies investigated different study populations and used different definitions for outcome, which makes it difficult to extract generalizable conclusions. The current knowledge gap concerns predictors of recurrent ischemic stroke in the general ischemic stroke population. We conducted a systematic review of both clinical and imaging predictors of recurrent ischemic stroke and performed a meta-analysis of the current literature.

\section{Methods}

\section{Search Strategy and Selection}

We performed a systematic search in PubMed, Embase, Cochrane Library, and CINAHL up to September 2017 by using synonyms of "ischemic stroke" and "predictors/determinants" and "recurrence" (online suppl. Table I; for all online suppl. material, see www.karger.com/doi/10.1159/000490422). One author (F.K.) screened articles on the title and abstract for relevance by using the following inclusion criteria: unselected study population of patients with acute ischemic stroke, outcome was recurrent ischemic stroke and, effect estimate (risk ratio [RR], OR or hazard ratio [HR]) including 95\% CI was reported or could be calculated (online suppl. Fig. I). Animal studies, studies in languages other than English, Dutch, German, French, or Spanish, case series, reviews, conference abstracts, and editorials were excluded for further review. Full-text screening was done independently by 2 authors (F.K. and R.T.). In case of disagreement between authors on the selected studies, consensus was achieved by means of discussion. Additional relevant papers were retrieved by means of a cross-reference check. To obtain comparable series of patients, series including patients with TIAs and series that were selected on age or stroke subtype were excluded. All supporting data are available within this article and its online supplements. This review was performed following the Preferred Reporting Items for Systematic Reviews and Meta-Analyses criteria [9].

\section{Critical Appraisal}

The relevance and validity of the included studies were appraised by 2 authors (F.K. and R.T.). A quality assessment score was formulated, which was based on the Newcastle Ottawa Quality Assessment Scale [10]. Furthermore, we added additional topics to the quality assessment score including study design, analyses, and outcome definition as has been done before in other systematic reviews (online suppl. Table II) [11-13]. If the quality assessment score was below 10 , the study was excluded for the primary meta-analysis.

\section{Level of Evidence}

The reported determinants were deemed as predictive, nonpredictive, or inconsistent based on consistency of the reported estimates and clinical relevance (Fig. 1) [12]. In addition, every predictive or non-predictive determinant was given a level of evidence based on the amount of studies with (non-) significant estimates.

\section{Data Extraction}

Baseline characteristics of the included studies were collected including sample size and follow-up duration. RR, ORs, and $\mathrm{HR}$ on relevant outcome measures with corresponding 95\% CI were extracted. In the absence of the relevant effect estimates, RRs were calculated using crude data. Two-by-two tables were formed and the RR was calculated using the following formula: $R R=(a /[a+b]) /(c /[c+d])$.

\section{Statistical Analysis}

The weighted incidence rate with 95\% CI and weighted mean follow-up duration were calculated by weighing the studies on sample size. When 2 or more RRs were present per predictor, the pooled RRs with $95 \%$ CIs were computed by using the inverse variance random effects models in Review Manager (Review Manager (RevMan). Version 5.3. Copenhagen: The Nordic Cochrane Centre, The Cochrane Collaboration, 2014). Heterogeneity was quantified by calculating $I^{2}$ as a percentage. A low level of heterogeneity was present when $I^{2}$ was $25 \%$, a moderate level when $I^{2}$ was $50 \%$ and a high level when $I^{2}$ was 75\% [14]. Determinants were included for analysis only if multiple univariable RRs were available. A $p$ value smaller than 0.05 was considered significant. To check for differences between low and high-quality studies, we performed a second meta-analysis including all the studies that were assessed for quality.

\section{Results}

Out of 2,173 unique articles we included 16 studies for quality assessment (online suppl. Fig. I). Most studies were excluded because of selected study populations and deviating definitions of outcome. Six studies were excluded due to low-quality scores (Table 1) [15-20]. Two studies used the same study population but investigated different determinants for the recurrence of ischemic stroke: one study investigated multiple predictors, while the other specifically focused on diabetes mellitus [21, 22]. We 


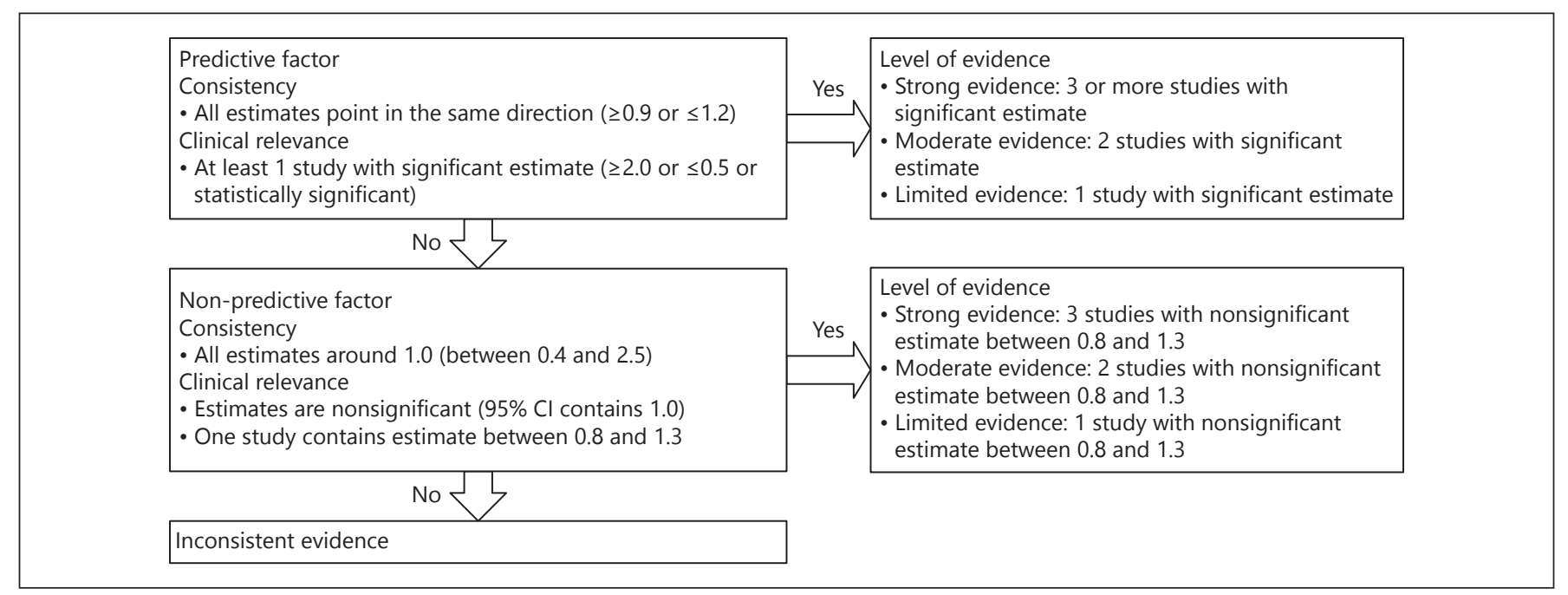

Fig. 1. Criteria for level of evidence.

included both studies because each study provides additional information for this review. Finally, 10 studies remained for meta-analysis including 6 prospective cohort and 4 retrospective cohort studies [3, 4, 21-28]. The included studies investigated a total of 212,864 patients with ischemic stroke. The weighted incidence rate of recurrent ischemic stroke was 99 (95\% CI 98-101) per 1,000 person-years with a weighted mean follow-up duration of 13 months.

\section{Predictive Factors}

Clinical and imaging predictors of recurrent ischemic stroke are reported in Table 2 and visualized in Figure 2. Strong level of evidence for the prediction of recurrent ischemic stroke was found for previous history of stroke or TIA with significant RRs ranging from 1.8 to 3.4 in 4 studies. Small vessel disease as compared to large artery atherosclerosis was associated with a lower chance of recurrence (pooled RR 0.3, 95\% CI 0.1-0.7). Moderate level of evidence was found for a lower risk of an undetermined cause of stroke as compared to large artery atherosclerosis (pooled RR 0.5, 95\% CI 0.2-1.1).

No predictive imaging factors based on CT or ultrasound were found. A moderate level of evidence for the prediction of recurrent ischemic stroke based on MRI was found for multiple lesions, multiple stage lesions, multiple territory lesions, chronic infarcts, and isolated cortical lesions, which are defined in online supplemental Table III. A limited level of evidence was present for the association between white matter lesions and recurrence of ischemic stroke (pooled RR 1.5, 95\% CI 0.9-2.6). A second meta-analysis including all the studies that were assessed for quality (Table 1) did not provide substantial different results compared to the analysis of the high quality studies (online suppl. Table IV).

A single large $(n=196,765)$ Swedish study [4] reported the following positive and negative predictors of recurrent ischemic stroke during a one-year followup: age 76-85 years vs. age 18-65 years (HR 1.1, 95\% CI 1.1-1.2), prior ischemic stroke (HR 1.3, 95\% CI 1.21.4), prior myocardial infarction (HR 1.3, 95\% CI 1.21.3), diabetes mellitus (HR 1.2, 95\% CI 1.1-1.3), atrial fibrillation without warfarin treatment (HR 1.6, 95\% CI 1.5-1.7), atrial fibrillation with warfarin treatment (HR $0.8,95 \%$ CI 0.7-0.9), use of acetylsalicylic acid (HR 0.9, 95\% CI 0.9-1.0), use of acetylsalicylic acid in combination with dipyridamole (HR $0.9,95 \%$ CI $0.6-0.9$ ), and use of lipid lowering medication $(0.9,95 \%$ CI $0.8-0.9)$. The reported predictors were further adjusted for female sex (HR 1.0, 95\% CI 0.9-1.0) and medication use including clopidogrel (HR 1.1, 95\% CI 1.0-1.2), calcium channel blockers (HR 1.0, 95\% CI 1.0-1.1), betablockers (HR 1.2, 95\% CI 1.2-1.3), diuretics (HR 1.1, 95\% CI 1.0-1.1), and angiotensin converting enzyme (ACE) inhibitors (HR 1.0, 95\% CI 1.0-1.0).

\section{Non-Predictive Factors}

Factors that were not predictive of recurrent ischemic stroke in at least 3 studies (strong level of evidence) were male sex, hypertension, dyslipidemia, diabetes mellitus, atrial fibrillation, use of anticoagulant medication, use of 
Table 1. Characteristics of the studies included for quality assessment

\begin{tabular}{|c|c|c|c|c|c|c|c|c|}
\hline $\begin{array}{l}\text { Study } \\
\text { Country }\end{array}$ & Study design & $\begin{array}{l}\text { Sample size } \\
\text { total, } n\end{array}$ & $\begin{array}{l}\text { Sample size } \\
\text { eligible, } n\end{array}$ & $\begin{array}{l}\text { Recurrences, } \\
n(\%)\end{array}$ & $\begin{array}{l}\text { Follow-up } \\
\text { duration }\end{array}$ & Determinants & Estimate & $\begin{array}{l}\text { Quality } \\
\text { score }\end{array}$ \\
\hline Alter et al. [21], $1997^{\dagger}$, USA & Prospective & 621 & 621 & $77(12)$ & 24 months & $\mathrm{DM}$ & uv $\mathrm{RR}^{\ddagger}$ & 12 \\
\hline Ay et al. [23], 2010, USA & Retrospective* & 1,458 & 1,458 & $60(4)$ & 90 days & $\begin{array}{l}\text { Demographics, CVRF, stroke } \\
\text { subtype, medication, imaging }\end{array}$ & $\begin{array}{l}\text { uv RR } R^{\ddagger} \text { uv HR; mv } \\
\beta \text {-coefficient }\end{array}$ & 11 \\
\hline Bergström et al. [4], 2017, Sweden & Retrospective* & 196,765 & 196,765 & $22,198(13)^{\S}$ & 1 year & $\begin{array}{l}\text { Demographics, CVRF, } \\
\text { medication }\end{array}$ & mv HR & 11 \\
\hline Buenaflor et al. [3], 2017, Philippines & Retrospective & 1,155 & 1,155 & $280(24)$ & 3 years & Demographics, CVRF & uv OR; uv $\mathrm{RR}^{\ddagger}$ & 10 \\
\hline Grau et al. [15], 2001, Germany & Prospective & 5,017 & 5,017 & $216(4)$ & 7 days & Stroke subtype & $\mathrm{uv} \mathrm{RR}^{\ddagger}$ & 9 \\
\hline Hankey et al. [16], 1998, Australia & Prospective & 343 & 250 & $33(13)$ & 5 years & Stroke subtype & $\mathrm{uv} \mathrm{RR}^{\ddagger}$ & 9 \\
\hline Hillen et al. [17], 2003, UK & Prospective & 1,626 & 1,166 & $80(7)$ & 5 years & LACI vs. non-LACI & $\mathrm{uv} \mathrm{RR}^{\ddagger}$ & 9 \\
\hline Hirayama et al. [18], 2010, Japan & Case control & 374 & 374 & $72(19)$ & 3.1 years & Demographics, CVRF & $\mathrm{uv} \mathrm{RR}^{\ddagger}$ & 8 \\
\hline Kim et al. [24], 2014, USA & Retrospective & 2,378 & 2,378 & $106(4)$ & 90 days & $\begin{array}{l}\text { Demographics, CVRF, stroke } \\
\text { subtype, medication, imaging }\end{array}$ & uv $\mathrm{RR}^{\ddagger} ; \mathrm{uv}$ and $\mathrm{mv} \mathrm{HR}$ & 11 \\
\hline Kuwashiro et al. [25], 2012, Japan & Prospective & 260 & 260 & $25(10)$ & 12 months & $\begin{array}{l}\text { Demographics, CVRF, } \\
\text { biometry, laboratory, stroke } \\
\text { subtype, medication }\end{array}$ & uv $\mathrm{RR}^{\ddagger} ; \mathrm{mv} \mathrm{OR}$ & 11 \\
\hline Lai et al. [22], 1994 ${ }^{\dagger}$, USA & Prospective & 621 & 621 & $77(12)$ & 24 months & $\begin{array}{l}\text { Hypertension, atrial } \\
\text { fibrillation }\end{array}$ & mv HR & 10 \\
\hline Lee et al. [26], 2004, Australia & Retrospective & 7,816 & 7,816 & $743(10)$ & 4 years & $\begin{array}{l}\text { Demographics, CVRF, } \\
\text { carotid endarterectomy }\end{array}$ & mv HR & 11 \\
\hline Nam et al. [27], 2017, South Korea & Retrospective & 959 & 959 & $63(7)$ & 31 months & $\begin{array}{l}\text { Demographics, CVRF, stroke } \\
\text { subtype, medication, imaging }\end{array}$ & uv $\mathrm{RR}^{\ddagger} ; \mathrm{uv}$ and $\mathrm{mv} \mathrm{HR}$ & 11 \\
\hline Omori et al. [19], 2015, Japan & Retrospective* & 1,087 & 991 & $232(21)$ & 704 days & $\begin{array}{l}\text { Demographics, family } \\
\text { history, stroke subtype, mRS } \\
\text { at discharge }\end{array}$ & uv $\mathrm{RR}^{\ddagger} ; \mathrm{mv}$ OR & 8 \\
\hline Soda et al. [28], 2004, Japan & Prospective & 831 & 831 & $65(8)$ & 12 months & $\begin{array}{l}\text { Demographics, CVRF, } \\
\text { medication }\end{array}$ & uv $\mathrm{RR}^{\ddagger}$, adjusted $\mathrm{RR}$ & 12 \\
\hline Suanprasert et al. [20], 2011, Thailand & Case control & 234 & 234 & $67(29)$ & 13 months & $\begin{array}{l}\text { Demographics, CVRF, stroke } \\
\text { subtype, medication }\end{array}$ & uv $\mathrm{RR}^{\ddagger} ; \mathrm{mv}$ OR & 7 \\
\hline $\begin{array}{l}\text { * From prospective database. } \\
\text { † Identical study populations, but } \\
\text { ^ Calculated by using crude data. } \\
\text { § Cumulative 1-year incidence. } \\
\text { USA, United States of America; DI } \\
\text { ACI, lacunar infarcts; RR, relative risl }\end{array}$ & M, diabetes mellit & sifferent pre & $\begin{array}{l}\text { edictors. } \\
\text { diovascular }\end{array}$ & factors; uv, $\mathrm{c}$ & variable; RR & sk ratio; HR, hazard ratio; mv, & ltivariable; UK, United & ingdom \\
\hline
\end{tabular}

antiplatelet medication, and statin use (online suppl. Table V). Furthermore, no association was found for alcohol use, and the use of antihypertensive medication with a moderate level of evidence.

\section{Inconsistent Factors}

Conflicting evidence was found for the association between smoking and recurrent ischemic stroke (online suppl. Table VI). Two out of 6 studies reported that smoking at baseline is significantly protective for recurrence of ischemic stroke. However, the remaining 4 studies provided neutral RRs. Conflicting evidence was also found for cardiac embolism as cause of the ischemic stroke com- pared to large artery atherosclerosis and for presence of prior cardiovascular disease. Only 2 studies provided univariable RRs for carotid intervention with broad confidence intervals.

\section{Discussion}

Strong evidence was found for past medical history of stroke or TIA and large rather than small vessel disease as predictors of recurrent ischemic stroke. There is a moderate level of evidence that patients with an undetermined cause of stroke had a more benign prognosis with respect 
Table 2. Predictive factors for recurrent ischemic stroke

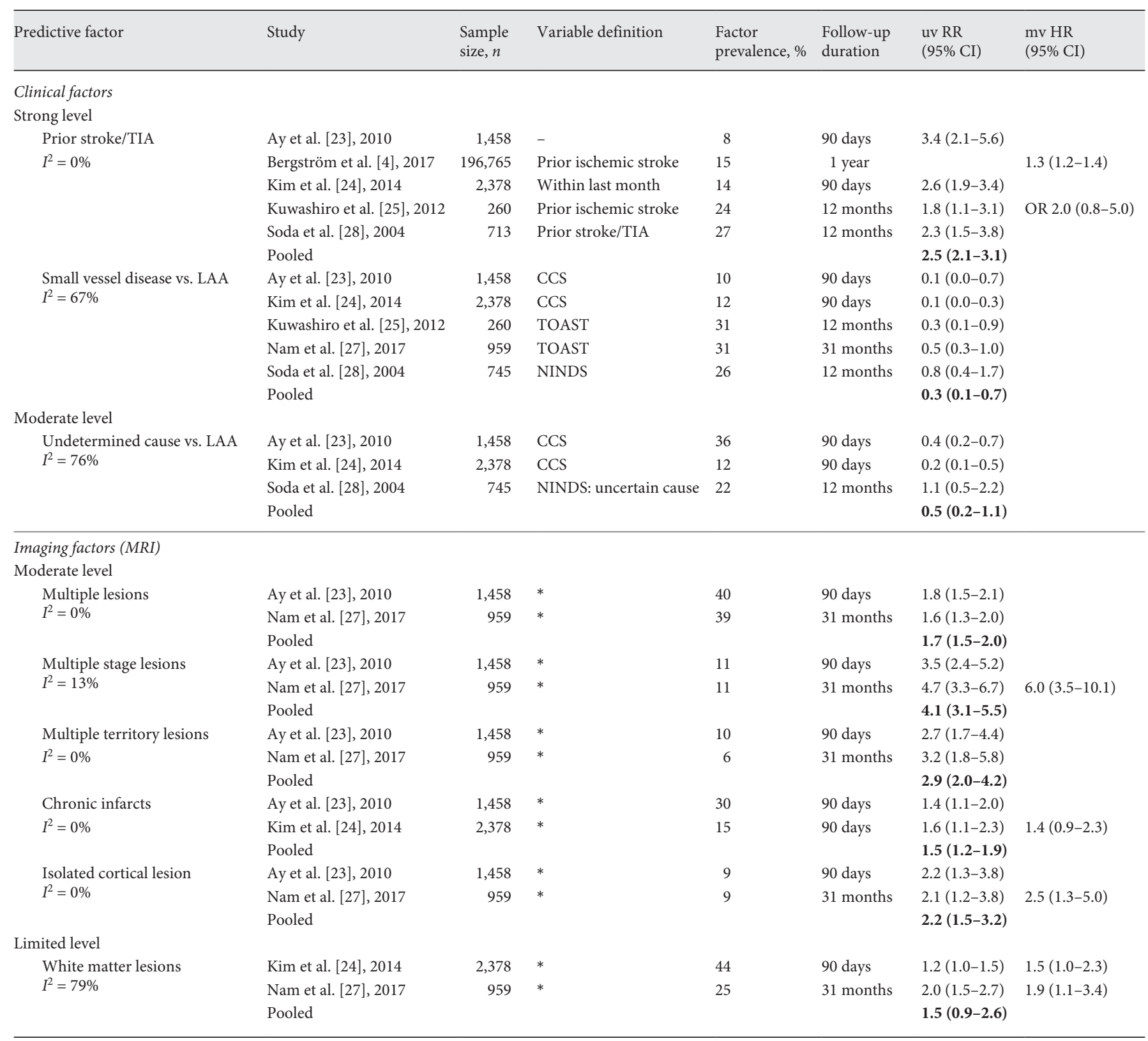

* Online supplementary Table III for definitions of imaging factors.

Pooled values in bold. uv, univariable; RR, risk ratio; mv, multivariable; HR, hazard ratio; TIA, transient ischemic attack; LAA, large artery atherosclerosis; CCS, Causative Classification System for ischemic stroke; TOAST, Trial of ORG 10172 in Acute Stroke Treatment; NINDS, National Institute of Neurological Diseases and Stroke.

to recurrent ischemic stroke than patients with large artery atherosclerosis. Negative associations were found for atrial fibrillation with warfarin treatment, use of acetylsalicylic acid, use of acetylsalicylic acid in combination with dipyridamole and use of lipid-lowering medication. When considering imaging predictors, a strong level of evidence was absent, but a moderate level of evidence was found for the association between recurrent ischemic stroke and the load of ischemic lesions on MRI.

No other systematic review focusing on prediction of recurrent ischemic stroke after recent ischemic stroke was found. We had to exclude several studies that studied clinical and imaging predictors of ischemic stroke because these studies investigated heterogeneous stroke 


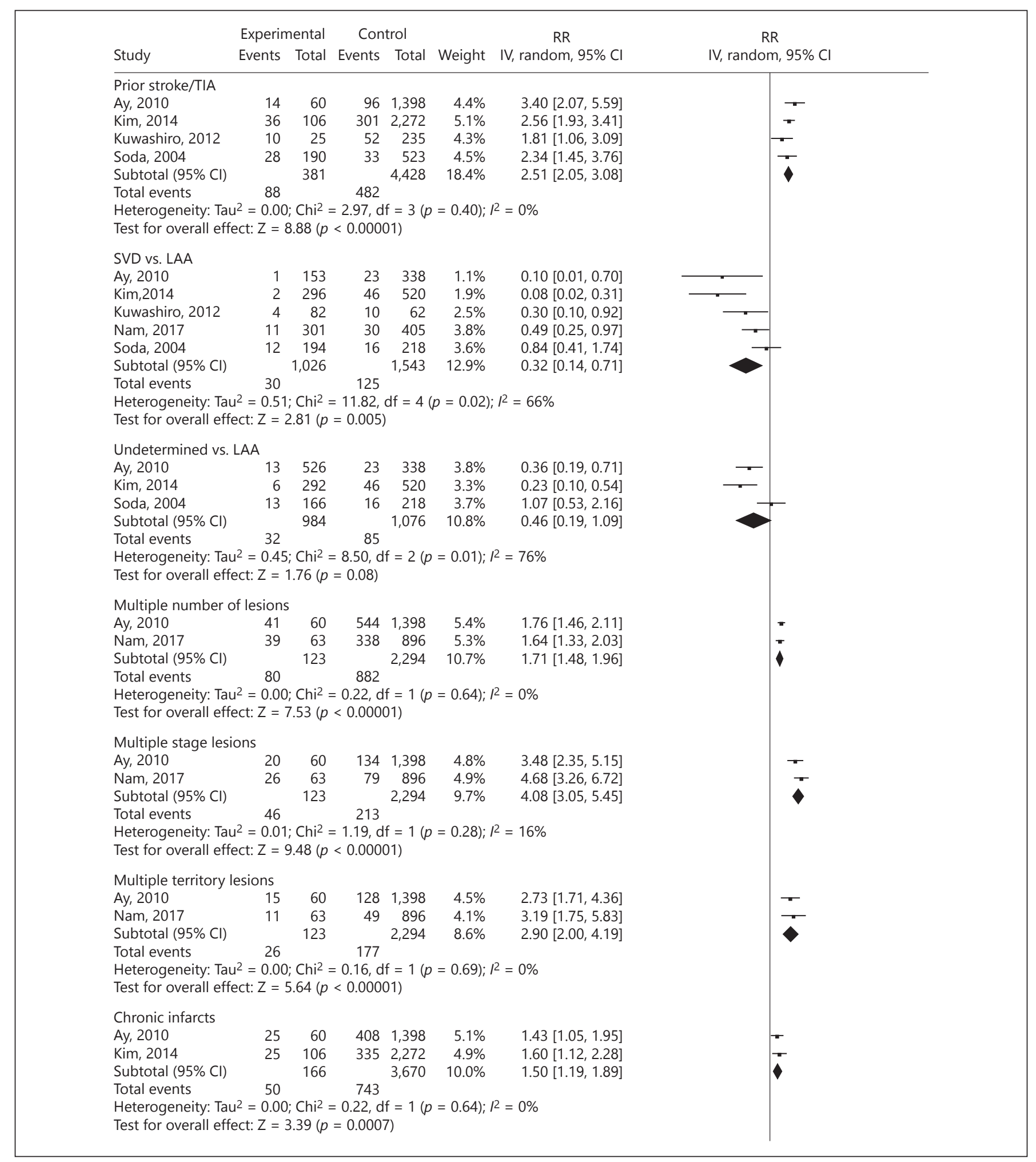

Fig. 2. Forest plot of predictors of recurrent ischemic stroke. IV, inversed variance; TIA, transient ischemic attack; SVD, small vessel disease; LAA, large artery atherosclerosis.

(For figure 2 see next pages.) 


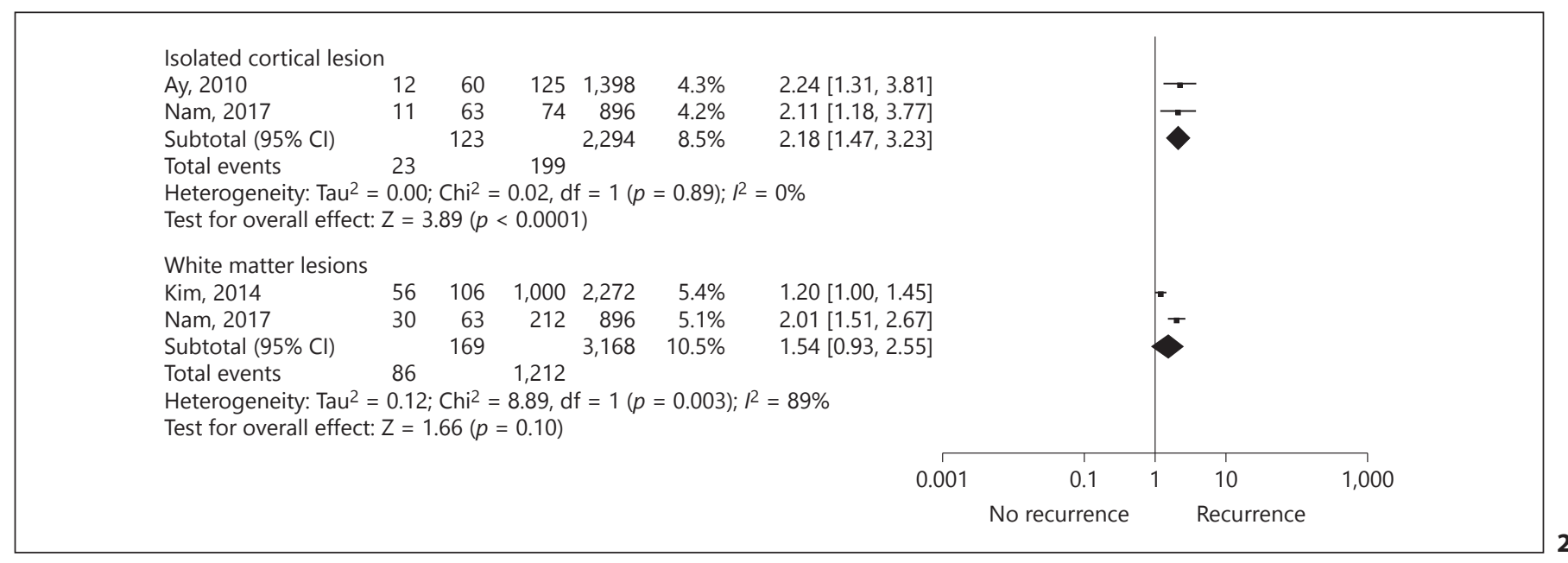

populations or subgroups of the general stroke population. For instance, several studies studied both patients with ischemic stroke and patients with a TIA. Since predictors of ischemic stroke recurrence differ between subgroups of the general stroke population and the general stroke population, the need for studying unselected study populations should be emphasized. Other studies that were excluded investigated predictors of recurrent stroke including hemorrhagic stroke. Several studies used recurrence of both hemorrhagic and ischemic stroke as outcome and they found that white matter lesions on MRI are associated with stroke recurrence, while in our metaanalysis, in which only recurrent ischemic stroke was used as outcome, only 2 studies provided evidence for this association $[29,30]$.

We chose to exclude hemorrhagic recurrences as outcome because causative mechanisms differ between ischemic and hemorrhagic stroke, which in turn may be related to recurrence. Similarly, causative mechanisms may differ between early and late recurrences of ischemic stroke. In our study, we could not analyze early and late recurrences separately because longitudinal data on recurrences were not provided. Future studies need to elucidate whether early and late recurrences of ischemic stroke indeed differ in causative mechanisms, how these outcomes should be defined and whether prediction models of recurrent ischemic stroke need to be adjusted for those differences.

It remains difficult to evaluate a possible association between the clinical predictors and the imaging findings. In this review, the prognostic imaging factors seem compatible with the reported clinical predictors. Previous ischemic events may lead to brain damage that can be seen on MRI. Furthermore, atherosclerosis of large arteries such as the internal carotid artery has been associated with multiple white matter lesions on MRI [31]. We think that the combination of baseline clinical and imaging factors remains vital for predicting recurrent ischemic stroke. If prior cardiovascular events are absent based on history taking, imaging studies may elucidate "silent" cerebrovascular disease, which has been associated with future stroke $[32,33]$. To improve prediction models, the role of imaging needs to be established and, more specifically, future imaging studies should focus on determining the cause of stroke and previous ischemic brain damage.

Atrial fibrillation was not of predictive value according to our pooled findings. In the Swedish stroke registry study, patients with atrial fibrillation were divided in 2 groups: one group receiving anticoagulant treatment and one group not receiving anticoagulant treatment [4]. In multivariable analysis, anticoagulant treatment was associated with decreased risk of ischemic stroke recurrence, while no treatment was predictive for recurrence. Based on clinical risk scores, anticoagulant therapy is only indicated when the risk of ischemic stroke outweighs the risk of hemorrhagic complications [34]. In the other included studies, treatment was not addressed when assessing atrial fibrillation as a predictor, which may be the reason of atrial fibrillation not being a predictor of recurrent ischemic stroke according to our review. These results indicate that future studies should address treatment strategies in atrial fibrillation as distinct predictors of ischemic stroke recurrence. Ideally, the effect of anticoagulant treatment on ischemic stroke recurrences in patients with recent ischemic stroke and atrial fibrillation should be in- 
vestigated in a randomized placebo-controlled manner. The same goes for the treatment of other risk factors, but ethical objections may be raised.

A strong point of this study was the fact that we used strict criteria for study domain and outcome and that we analyzed the selected studies according to the well-established Preferred Reporting Items for Systematic Reviews and Meta-Analyses criteria. Because we only included unselected study populations of ischemic stroke and only studies with ischemic stroke recurrence as outcome, heterogeneity between studies was low and generalizability was high. Despite the fact that we had to exclude several studies because of our strict selection criteria, a sufficient number of studies were found to provide strong level of evidence for certain predictors of recurrent ischemic stroke. Furthermore, the gaps in current literature concerning recurrent ischemic stroke are highlighted and thereby encourage investigators to fill those gaps.

A drawback of this study was the possible existence of publication bias. Studies that did not find significant estimates may have been averted from publication. We could not formally test publication bias because the amount of studies was too low. No funnel plots were generated, since they may not detect publication bias as less than 10 studies were available per category [35]. Heterogeneity between studies may have been an issue, because differences were present across studies with respect to number of study participants, follow-up durations, and definitions of predictors. Furthermore, patients may have been treated differently across studies because treatment protocols have been improved over the years. However, within the single studies, all patients received the same treatment. Hence, considering the limitations of this study, we anticipate that the mentioned sources of heterogeneity will have limited impact on our pooled results. As most heterogeneity percentages were low, strict selection procedures were followed and inverse variance random effects models were applied to adjust for variations across studies. Future studies should anticipate on these heterogeneity issues by using similar follow-up durations (e.g., 90 days) and similar definitions of cardiovascular risk factors, stroke subtypes, and imaging variables.

In conclusion, clinical predictors of ischemic stroke recurrence have been well established. The role of imaging predictors is less well established and only investigated for MRI, which emphasizes the need for further investigation of imaging to visualize characteristics and causes of (recurrent) ischemic stroke.

\section{Disclosure Statement}

The authors declare that they have no conflicts of interest to disclose.

\section{Funding Source}

None.

\section{References}

1 Dhamoon MS, Sciacca RR, Rundek T, Sacco RL, Elkind MS: Recurrent stroke and cardiac risks after first ischemic stroke: the Northern Manhattan Study. Neurology 2006;66:641646.

2 de la Cámara AG, Arche JFV, Vivas PF, Guzmán JD, del Pozo SVF, Cuadrado AR, Pareja FB: Recurrence after a first-ever ischemic stroke development of a clinical prediction rule. Res Neurol Int J 2013; 2013:13.

3 Buenaflor FGB, Navarro JC, Lara KJA, Venketasubramanian N: Recurrence rate of ischemic stroke: a single center experience. Austin J Cerebrovasc Dis Stroke 2017;4:1057.

4 Bergstrom L, Irewall AL, Soderstrom L, Ogren J, Laurell K, Mooe T: One-year incidence, time trends, and predictors of recurrent ischemic stroke in Sweden From 1998 to 2010: an observational study. Stroke 2017;48: 2046-2051.

5 Nam KW, Kwon HM, Lim JS, Han MK, Lee YS: Clinical relevance of abnormal neuroim- aging findings and long-term risk of stroke recurrence. Eur J Neurol 2017;24:1348-1354. 6 Amarenco P, Cohen A, Hommel M, Moulin T, Leys D, Bousser MG: Atherosclerotic disease of the aortic arch as a risk factor for recurrent ischemic stroke. NEngl J Med 1996;334:1216-1221.

7 Lee K, Hur J, Hong SR, Suh YJ, Im DJ, Kim YJ, Hong YJ, Lee HJ, Lee HS, Hong GR, Choi BW: Predictors of recurrent stroke in patients with ischemic stroke: comparison study between transesophageal echocardiography and cardiac CT. Radiology 2015;276:381-389.

8 O'Brien PJ, Thiemann DR, McNamara RL, Roberts JW, Raska K, Oppenheimer SM, Lima JA: Usefulness of transesophageal echocardiography in predicting mortality and morbidity in stroke patients without clinically known cardiac sources of embolus. Am J Cardiol 1998;81:1144-1151.

9 Moher D, Liberati A, Tetzlaff J, Altman DG: Preferred reporting items for systematic reviews and meta-analyses: the PRISMA statement. PLoS Med 2009;6:e1000097.
10 Higgins JPT, Green S: Chapter 13.5.2.3: Cochrane Handbook for Systematic Reviews of Interventions Version 510 (updated March 2011), The Cochrane Collaboration. Retrieved from www.handbook.cochrane.org, 2011.

11 Borghouts JA, Koes BW, Bouter LM: The clinical course and prognostic factors of non-specific neck pain: a systematic review. Pain 1998;77:1-13.

12 de Rooij NK, Rinkel GJ, Dankbaar JW, Frijns CJ: Delayed cerebral ischemia after subarachnoid hemorrhage: a systematic review of clinical, laboratory, and radiological predictors. Stroke 2013;44:43-54

13 Post B, Merkus MP, de Haan RJ, Speelman JD: Prognostic factors for the progression of Parkinson's disease: a systematic review. Mov Disord 2007;22:1839-1851;quiz 1988.

14 Higgins JP, Thompson SG, Deeks JJ, Altman DG: Measuring inconsistency in meta-analyses. BMJ 2003;327:557-560. 
15 Grau AJ, Weimar C, Buggle F, Heinrich A, Goertler M, Neumaier S, Glahn J, Brandt T, Hacke W, Diener HC: Risk factors, outcome, and treatment in subtypes of ischemic stroke: the German stroke data bank. Stroke 2001;32: 2559-2566.

16 Hankey GJ, Jamrozik K, Broadhurst RJ, Forbes S, Burvill PW, Anderson CS, StewartWynne EG: Long-term risk of first recurrent stroke in the Perth Community Stroke Study. Stroke 1998;29:2491-2500.

17 Hillen T, Coshall C, Tilling K, Rudd AG, McGovern R, Wolfe CD: Cause of stroke recurrence is multifactorial: patterns, risk factors, and outcomes of stroke recurrence in the South London Stroke Register. Stroke 2003; 34:1457-1463.

18 Hirayama T, Nakamura Y, Yoshii Y, Ikeda $\mathrm{K}$ : Clinicoradiological features of recurrent ischemic stroke: healthcare for poststroke patients. J Multidiscip Healthc 2010;3: 97-101.

19 Omori T, Kawagoe M, Moriyama M, Yasuda T, Ito Y, Hyakuta T, Nagatsuka K, Matsumoto M: Multifactorial analysis of factors affecting recurrence of stroke in Japan. Asia Pac J Public Health 2015;27:NP333-NP340.

20 Suanprasert N, Tantirithisak T: Impact of risk factors for recurrent ischemic stroke in Prasat Neurological Institute. J Med Assoc Thai 2011;94:1035-1043.

21 Alter M, Lai SM, Friday G, Singh V, Kumar VM, Sobel E: Stroke recurrence in diabetics. Does control of blood glucose reduce risk? Stroke 1997;28:1153-1157.
22 Lai SM, Alter M, Friday G, Sobel E: A multifactorial analysis of risk factors for recurrence of ischemic stroke. Stroke 1994;25:958-962.

23 Ay H, Gungor L, Arsava EM, Rosand J, Vangel M, Benner T, Schwamm LH, Furie KL, Koroshetz WJ, Sorensen AG: A score to predict early risk of recurrence after ischemic stroke. Neurology 2010;74:128-135.

24 Kim GM, Park KY, Avery R, Helenius J, Rost N, Rosand J, Rosen B, Ay H: Extensive leukoaraiosis is associated with high early risk of recurrence after ischemic stroke. Stroke 2014; 45:479-485.

25 Kuwashiro T, Sugimori H, Kamouchi M, Ago T, Kitazono T, Iida M: Lower levels of highdensity lipoprotein cholesterol on admission and a recurrence of ischemic stroke: a 12-month follow-up of the Fukuoka Stroke Registry. J Stroke Cerebrovasc Dis 2012;21: 561-568.

26 Lee AH, Somerford PJ, Yau KK: Risk factors for ischaemic stroke recurrence after hospitalisation. Med J Aust 2004;181:244-246.

27 Nam KW, Kwon HM, Lim JS, Han MK, Lee YS: Clinical relevance of abnormal neuroimaging findings and long-term risk of stroke recurrence. Eur J Neurol 2017;24:1348-1354.

28 Soda T, Nakayasu H, Maeda M, Kusumi M, Kowa H, Awaki E, Saito J, Nakashima K: Stroke recurrence within the first year following cerebral infarction-Tottori University Lacunar Infarction Prognosis Study (TULIPS). Acta Neurol Scand 2004;110:343-349.

$29 \mathrm{Fu} \mathrm{JH}, \mathrm{Lu} \mathrm{CZ}$, Hong Z, Dong Q, Luo Y, Wong KS: Extent of white matter lesions is related to acute subcortical infarcts and predicts further stroke risk in patients with first ever ischaemic stroke. J Neurol Neurosurg Psychiatry 2005;76:793-796.

30 Ntaios G, Lip GY, Lambrou D, Papavasileiou V, Manios E, Milionis H, Spengos K, Makaritsis K, Vemmos K: Leukoaraiosis and stroke recurrence risk in patients with and without atrial fibrillation. Neurology 2015;84:1213-1219.

31 de Leeuw FE, de Groot JC, Bots ML, Witteman JC, Oudkerk M, Hofman A, van Gijn J, Breteler MM: Carotid atherosclerosis and cerebral white matter lesions in a population based magnetic resonance imaging study. J Neurol 2000;247:291-296.

32 Vermeer SE, Hollander M, van Dijk EJ, Hofman A, Koudstaal PJ, Breteler MM: Silent brain infarcts and white matter lesions increase stroke risk in the general population: the Rotterdam Scan Study. Stroke 2003;34: 1126-1129.

33 Gioia LC, Tollard E, Dubuc V, Lanthier S, Deschaintre Y, Chagnon M, Poppe AY: Silent ischemic lesions in young adults with first stroke are associated with recurrent stroke. Neurology 2012;79:1208-1214.

34 Lip GY, Nieuwlaat R, Pisters R, Lane DA, Crijns HJ: Refining clinical risk stratification for predicting stroke and thromboembolism in atrial fibrillation using a novel risk factorbased approach: the euro heart survey on atrial fibrillation. Chest 2010;137:263-272.

35 Lau J, Ioannidis JPA, Terrin N, Schmid CH, Olkin I: The case of the misleading funnel plot. BMJ 2006;333:597-600. 